\title{
DEVELOPING A NORTH AMERICAN STATIC HAZARD PERCEPTION TEST
}

\author{
John Lyon, David Borkenhagen, Charles Scialfa, \\ Micheline Deschênes, \& Mark Horswill \\ University of Calgary \\ Calgary, Alberta, Canada \\ Email: scialfa@ucalgary.ca
}

\begin{abstract}
Summary: We examined the ability of young novice $(\mathrm{M}=.19$ yrs experience) and experienced drivers ( $\mathrm{M}=5.1$ yrs experience) to identify and localize frequently encountered roadway hazards using static images taken in western Canada. Dependent measures also included subjective ratings of hazard risk and scene clutter. Novice drivers reacted to roadway hazards more slowly while rating them as being less hazardous than young, experienced drivers. Using a small subset of scenes, it was determined that a brief hazard perception test employing static images could classify individuals with high accuracy (78\%) and good reliability (Cronbach's alpha $=.91)$.
\end{abstract}

\section{INTRODUCTION}

Driving is one of the more risky behaviours in which people engage in terms of injury, death, or related costs. Although many individuals drive with appropriate caution, there are some groups, particularly novice drivers, which are at greater risk for accident involvement (McKnight \& McKnight, 2003). In an attempt to increase driving safety, several measures have focused on novice drivers including graduated licensing, systematic and consistent on-road training, and rigorous examinations for licensure. Included in this last category are hazard perception assessments to identify an individual's ability to both detect and respond to common roadway hazards.

There are several reasons why novice drivers are deficient in hazard perception. It has been found that they do not scan the roadway efficiently (Chapman, Underwood, \& Roberts, 2002; Falkmer \& Gregersen, 2005; Pradhan et al., 2005; Underwood, Chapman, Bowden, \& Crundall, 2002) and so hazards that are identified by other more experienced drivers may go unnoticed. It may also be the case that novice drivers have an underdeveloped mental model of roadway hazards that might be present in driving situations (Horswill \& McKenna, 2004; Underwood et al., 2002).

Typically, a series of video-based dynamic scenes of hazardous situations have been incorporated into a hazard perception test. These tests have so far been employed in both Australia and the United Kingdom. These assessments take approximately 14 minutes to complete (e.g., DirectGov, 2009; Queensland Department of Transport and Main Roads, 2009). As dynamic video-based tests can be difficult to develop and administer on a large scale, it may be beneficial to develop a hazard perception assessment using static images of typical roadway hazards and situations. A static image test could be administered in a short period of time while including a variety of traffic situations. Assessing hazard perception ability by use of a standardized staticphotograph assessment in North America has yet to be extensively investigated. 
This research had three main goals. First, we wanted to determine if performance on a North American hazard perception test could discriminate between novice and experienced young drivers. Second, as there was some evidence suggesting that novice drivers are not capable of estimating hazard risk, we hypothesized that hazard ratings would be lower for novice drivers. Lastly, as it is frequently the cluttered scenes that are most demanding for hazard perception (e.g., Ho, Scialfa, Caird, \& Graw, 2001), we examined the relationships between driving experience, subjective clutter ratings and latencies to roadway hazards.

\section{METHOD}

Fifty-six drivers participated in the current study. One group consisted of 27 young experienced drivers aged 18-25 years old who had a valid license for two or more years. A second group consisted of 29 young novice drivers aged 16-25 years old with a maximum of six months driver experience. Participants were given either partial course credit or received \$20 (CDN) for their participation.

Summary demographic data are shown in Table 1. As the study utilized undergraduate Psychology students both driver groups were of similar age. Due to the fact that the majority of undergraduate Psychology students are female the sample was similarly biased. Experienced drivers had more years of formal education and more years of driving experience. Common to both groups was large variability of distance driven in the year previous to participation.

Table 1. Demographic data by driver experience group

\begin{tabular}{lrrr}
\hline Demographic Information & $\begin{array}{r}\text { Experienced }(\mathrm{n}=26) \\
\text { Mean }(S D)\end{array}$ & $\begin{array}{r}\text { Novice }(\mathrm{n}=25) \\
\text { Mean }(S D)\end{array}$ & $p$-value \\
\hline Age (yr) & $20.4(1.6)$ & $19.9(2.2)$ & .346 \\
Gender (M/F) & $(7 / 19)$ & $(9 / 16)$ & .346 \\
Number of years education $(\mathrm{yr})$ & $15.5(2.1)$ & $14.1(1.6)$ & .008 \\
Number of years Licensed $(\mathrm{yr})$ & $5.1(2.0)$ & $.19(.19)$ & $<.001$ \\
Distance driven in last year $(\mathrm{km})$ & $15173.6(11550.0)$ & $1556.0(3430.0)$ & $<.001$ \\
\hline
\end{tabular}

\section{Stimuli and Apparatus}

Initially, 120 driving images (see Figure 1 for example) were presented in three, eight-minute blocks consisting of 40 images each. One hundred of these images (83\%) contained a predetermined hazard. Hazards were defined as situations in which a collision (or near collision) between the driver and another road user would occur or had the potential to occur unless the driver reacted with an evasive action such as slowing, stopping, or steering. The other 20 images did not contain hazards and were included in an effort to modulate the observer's criterion for making a response. Each image was presented for four seconds during which time the participant was able to respond. 


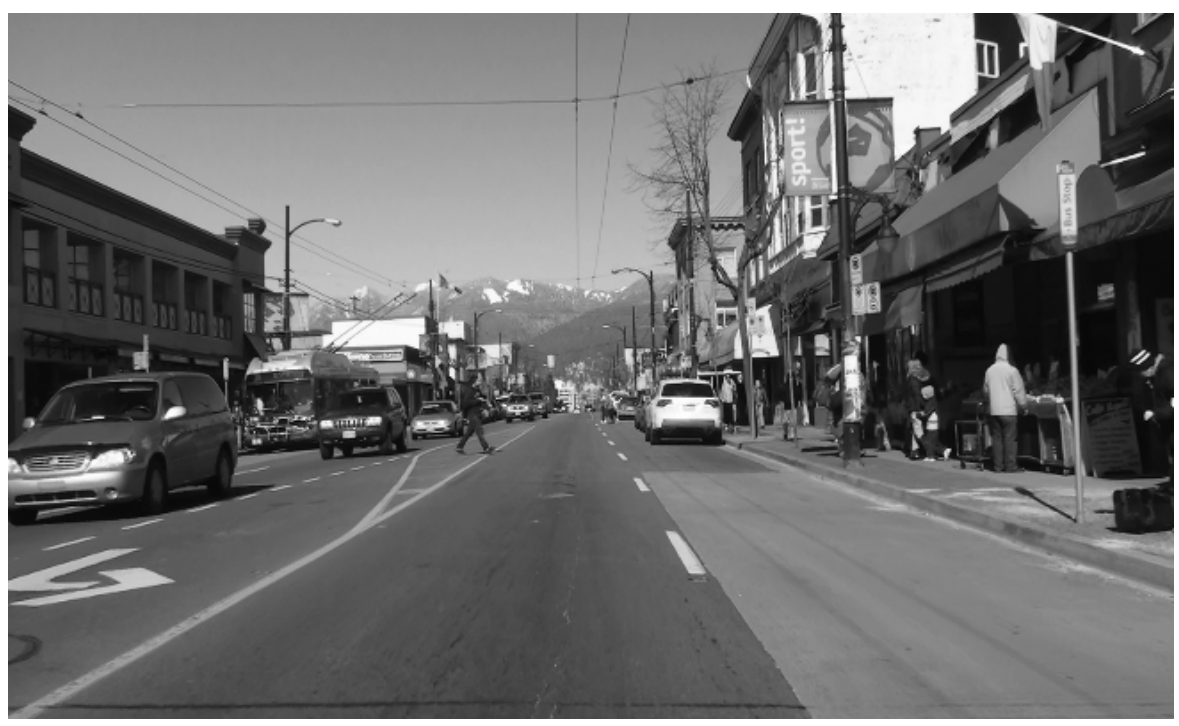

Figure 1. A static image of a potential roadway hazard

Images were recorded in Vancouver, BC and surrounding areas using a camera mounted in an effort to reflect a driver's-eye view of the roadway ahead. Static images were developed from a bank of driving videos gathered for a previous study (Scialfa, et al., 2011). All images were presented on a 17-inch Elo TouchSystems (1729L) touch-sensitive LCD monitor with a resolution of $1280 \times 1024$, set at a viewing distance of $40-45 \mathrm{~cm}$. The touch-sensitive monitor was used as a stimulus display and to collect touch-responses.

Measures included reaction time, hazard risk rating (5-point Likert-type scale), and scene clutter rating (5-point Likert-type scale). Participants also completed a demographic questionnaire containing questions regarding age, education, driving experience, and distance driven in the year previous to participation.

\section{Procedure}

Participants completed all tasks within a one-hour session. They first completed the demographic and driving experience questionnaire. Once completed, participants became familiar with the touch screen by completing a spatial RT task and seven practice trials identical to those trials encountered in the experiment proper. During this practice and familiarization, feedback regarding participant responses and repetition of the definition of a roadway hazard was given. Next, participants completed the full 120-image hazard perception task. Following the presentation of each image, participants also provided ratings of hazard risk and clutter.

\section{RESULTS}

Young experienced drivers responded faster than novice drivers in $70 \%$ of the hazard images, a trend that was significant via binomial test $(p<.05)$. However, at the individual level, $t$-tests yielded only eight images where novice drivers were significantly slower than experienced drivers. 
As the goal of the study was to develop a brief hazard perception test in North America a subset of 21 images was selected. Summary data corresponding to these 21 images are shown in Table 2. These images had at least $85 \%$ of experienced drivers touching the pre-determined hazard and at least a 200 ms reaction time difference favouring the experienced drivers. Within these 21 images it was found that novices ( $M=2.06$ seconds, $S D=.26$ seconds) were significantly slower than experienced $(M=1.75$ seconds, $S D=.35$ seconds $)$ drivers $(p=.001)$ and had a significantly higher $(M=.96)$ hit proportion $(p=.004)$ than novices $(M=.90)$. Using this subset of images we were able to predict group membership (Chi-squared $=15.94, p<.001$, Negelkerke $R^{2}=.36$ ) with a classification accuracy of $78.4 \%$, sensitivity of $84 \%$, and a specificity of $73.1 \%$. The internal consistency (Cronbach's alpha) of this 21-image test was .91.

Table 2. Descriptive statistics for 21 images that discriminate experienced and novice drivers

\begin{tabular}{lrrr}
\hline Value & $\begin{array}{r}\text { Experienced Mean } \\
(S D)\end{array}$ & $\begin{array}{r}\text { Novice } \\
\text { Mean }(S D)\end{array}$ & $p$-value \\
\hline Hit Rate & $95.80(4.90)$ & $89.90(9.26)$ & .011 \\
RT & $1.75(.35)$ & $2.06(.26)$ & $<.001$ \\
Hazard Rating & $2.94(.58)$ & $2.56(.61)$ & .001 \\
Clutter Rating & $2.40(.54)$ & $2.11(.54)$ & .043 \\
\hline
\end{tabular}

Out of the 100 images containing a hazard, 95 images produced a higher mean hazard rating from the experienced drivers $(M=3.11, S D=.56)$ than from the novice drivers $(M=2.75, S D=$ $.56)$, a significant trend via binomial test $(p<.05)$. Additionally, these 95 images produced a higher mean clutter rating for the experienced drivers $(M=2.65, S D=.57)$ than the novice drivers $(M=2.33, S D=.53)$, a significant trend via binomial test $(p<.05)$. As shown in Table 3 , after performing a median-split on hazard and clutter score it was found that images rated higher in hazard risk and low in clutter produced the shortest response times while those images rated as low hazard risk and high in perceived clutter produced the longest response times.

Table 3. Mean response latency as a function of hazard and clutter level

\begin{tabular}{lccc}
\hline \multirow{2}{*}{ Clutter Rating } & \multicolumn{3}{c}{ Hazard Rating } \\
\cline { 2 - 4 } & Low & High & Total \\
\hline Low & $1.91(.34)$ & $1.54(.18)$ & $1.79(.35)$ \\
High & $2.06(.36)$ & $1.73(.24)$ & $1.84(.33)$ \\
Total & $1.96(.35)$ & $1.67(.24)$ & \\
\hline
\end{tabular}

Note: Standard deviations in parentheses

\section{DISCUSSION}

Deficiencies in hazard perception are common among novice drivers (McKenna \& Crick, 1994; Pelz \& Krupat, 1974; Watts \& Quimby, 1979) and these deficiencies are associated with greater collision risk (Wells et al., 2008). There are several possible explanations for deficiencies in hazard perception including inefficient search of the driving environment (Chapman, Underwood, \& Roberts, 2002; Falkmer \& Gregersen, 2005; Pradhan et al., 2005; Underwood et al., 2002), increased risk-taking (Jonah, 1986) and poorly developed mental models of driving risk (Horswill \& McKenna, 2004; Underwood, et al., 2002). 
The current research makes two primary contributions to driving safety research. First, we have demonstrated that, in general, novice drivers respond more slowly than experienced drivers to a high proportion of still images of roadway hazards. Importantly, the effects of driving experience are independent of age, a confound that is often a limiting factor in studies of novice drivers. At the individual trial level, it is unlikely to find an image that produced significant group differences, but the proportion of trials showing mean differences favouring experienced drivers suggests that this is a systematic phenomenon not restricted to specific types of roadway hazards.

Second, we have demonstrated that a small subset of roadway hazard images can discriminate between novice and experienced drivers and that the resultant scale has reliability similar to other assessment tools (e.g., Congdon et al., 1999; Horswill \& McKenna, 2004; Raikos, 2003). Crucially, in comparison to dynamic hazard assessments currently in use (e.g., DirectGov, 2009; Queensland Department of Transport and Main Roads, 2009), this static assessment could be complete in under five minutes, a realistic time-commitment for large-scale use for North American markets.

Although the present attempt at developing a brief hazard perception test was successful at uncovering the systematic hazard perception differences between novice and experienced young drivers, several limitations present opportunities for future research. First, further investigation is needed to determine whether the results can be replicated with a sample including more male participants in an effort to closely match the general driving population. It may also be beneficial for a follow-up study to separate the experimental groups by greater amounts of years driving and kilometres driven per year to more closely match these driving groups in the general population.

\section{REFERENCES}

Chapman, P., Underwood, G. \& Roberts, K. (2002). Visual search patterns in trained and untrained novice drivers. Transportation Research Part F, 5, 157-167.

Congdon, P. (1999). The VicRoads hazard perception test: Can it predict accidents? Australian Council for Educational Research. VicRoads CR99-1.

DirectGov (2009). Retrieved August 13, 2009. http://www.direct.gov.uk/en/Motoring/LearnerAndNewDrivers/TheoryTest/DG_4022534.

Falkmer, T., \& Gregersen, N. P. (2005). A comparison of eye movement behavior of inexperienced and experienced drivers in real traffic environments. Optometry and Vision Science, 82, 73239.

Ho, G., Sciafla, C.T., Caird, J.K., \& Graw, T.(2001). Visual search for traffic signs: the effects of clutter, luminance, and aging. Human Factors. 43,194-207.

Horswill, M. S., \& McKenna, F. P. (2004). Drivers hazard perception ability: Situation awareness on the road. In S. Banbury \& S. Tremblay (Eds.). A Cognitive Approach to Situation Awareness, 155-175. Aldershot, UK: Ashgate.

Jonah, B. A. (1986). Youth and traffic accident risk: possible causes and potential solutions. Accident Analysis and Prevention, 18, 253-254. 
McKenna, F. P., \& Crick, J. L. (1994). Developments in hazard perception, Final Report. Department of Transport, UK.

McKnight, J.A., \& McKnight, S.A. (2003). Young novice drivers: Careless or clueless. Accident Analysis and Prevention, 35, 92125.

Pelz, D. C., \& Krupat, E. (1974). Caution profile and driving record or undergraduate males. Accident Analysis and Prevention, 6, 45-58.

Pradhan, A.K., Hammel, K.R., DeRamus, R., Pollatsek, A., Noyce, D.A., \& Fisher, D.L. (2005). The use of eye movements to evaluate the effects of driver age on risk perception in an advanced driving simulator. Human Factors, 47, 84052.

Queensland Department of Transport and Main Roads (2009). Everything you needed to know about the Hazard Perception Test. Retrieved online www.transport.qld.gov.au/hpt on February 17, 2010.

Raikos, M. K. (2003). Improving speed in skilled anticipation: The case of hazard perception in driving Unpublished honours thesis. School of Psychology, University of Queensland. Contact: m.horswill@psy.uq.edu.au.

Scialfa, C.T., Deschenes, M.C., Ference, J., Boone, J., Horswill, M.S., \& Wetton, M. (2011). A hazard perception test for novice drivers. Accident Analysis and Prevention, 43, 204-208.

Underwood, G., Chapman, P., Bowden, K., \& Crundall, D. (2002). Visual search while driving: skill and awareness during inspection of the scene. Transportation Research Part F, 5, 8797.

Watts, G. R., and Quimby, A. R. (1979), Design and validation of a driving simulator, Report LR 907. Transport and Road Research Laboratory, Crowthorne, UK.

Wells, P., Tong, S., Sexton, B., Grayson, G., \& Jones, E. (2008). Cohort II: A study of learner and new driver. Volume 1 Main report. Road Safety Research Report No. 81, Department of Transport, London. 